\title{
Establishment of the manufacturing conditions of hyssop (Hyssopus officinalis) -rice drink
}

\author{
Hak-Yoon Kim $^{1 *}$, Suk-Kyung Kim ${ }^{2}$ \\ ${ }^{1}$ Faculty of Environmemtal Studies, Keimyung University, Daegu 704-701, Korea \\ ${ }^{2}$ Wellmorning Ltd., Mungyeong 745-883, Korea
}

\section{히솝(Hyssopus officinalis)을 혼합한 쌀음료 제조조건 설정}

\author{
김학윤 ${ }^{*} \cdot$ 김숙경 ${ }^{2}$ \\ ${ }^{1}$ 계명대학교 환경학부, ${ }^{2}$ (주)웰모닝
}

\begin{abstract}
This study was monitored the quality characteristic of the hyssop-rice drink added using hyssop (Hyssopus officinalis) and rice. AFter operational parameters including amylase content $\left(X_{1}, 1 \sim 5 \mathrm{~mL}\right)$, saccharification time $\left(X_{2}, 10 \sim 18\right.$ hr) and hyssop content $\left(X_{3}, 1.0 \sim 3.0 \mathrm{~g}\right)$ were monitored, these results were analyzed using a response surface methodology for the determination of the optimum conditions (Brix, Hunter's color and organoleptic properties). Maximum conditions of Brix for the hyssop-rice drink were $0.96 \mathrm{~mL}$ of amylase, $14.93 \mathrm{hr}$ of saccharification time and $2 \mathrm{~g}$ of hyssop. Maximum conditions of Hunter's color $b$ were $1.90 \mathrm{~mL}$ of amylase, $16.64 \mathrm{hr}$ of saccharification time and 2.51 g of hyssop. Maximum conditions of organoleptic color were $4.60 \mathrm{~mL}$ of amylase, $15.66 \mathrm{hr}$ of saccharification time and $1.57 \mathrm{~g}$ of hyssop. Maximum conditions of organoleptic aroma were $3.46 \mathrm{~mL}$ of amylase, $10.79 \mathrm{hr}$ of saccharification time and $1.45 \mathrm{~g}$ of hyssop. Maximum conditions of organoleptic taste were $3.67 \mathrm{~mL}$ of amylase, $17.64 \mathrm{hr}$ of saccharification time and $1.76 \mathrm{~g}$ of hyssop. Maximum conditions of overall palatability of the hyssop-rice drink were $3.73 \mathrm{~mL}$ of amylase, $13.66 \mathrm{hr}$ of saccharification time and $1.85 \mathrm{~g}$ of hyssop.
\end{abstract}

Key words : Hyssopus officinalis, rice drink, organoleptic properties, Hunter's color, response surface methodology

\section{서 론}

최근 산업발달과 소득증대로 인해 식생활 양식이 크게 변화하고 있다. 특히 우리나라 국민의 주식인 쌀의 1 인당 연간 소비량은 매년 감소 추세에 있으며, 정부의 쌀 재고량 이 크게 증가하여 이를 저장하는데 많은 비용이 들고 있다. 정부에서는 쌀 재고량을 줄이기 위하여 1990년도부터 쌀 막걸리, 라면 등 여러 가지 식품가공에 쌀을 이용하도록 권장하고 있다(1). 쌀의 소비는 주로 주식인 밥으로 가장 많이 이용되고 있으며, 그 외에 주류, 떡, 과자 등으로 일부

*Corresponding author. E-mail : hykim@kmu.ac.kr

Phone : 82-53-580-5918, Fax : 82-53-580-5385

Received 18 May 2015; Revised 10 June 2015; Accepted 15 June 2015.

Copyright (c) The Korean Society of Food Preservation. All rights reserved.
가 이용되고 있으나 쌀을 이용한 가공식품 개발은 아직도 크게 증가하지 않고 있다(2)

꿀풀과의 다년생인 히솝(Hyssop, Hyssopus officinalis)은 성경에 우슬초로 기록되어 있으며 성스러운 향초라는 뜻을 지니고 있다. 구약에 열 번, 신약에 두 번 언급된 우슬초는 성경 시대의 히브리인들에게 매우 흔하지만 뚜렷한 특징을 가진 식물이었다(3). 성벽의 틈바구니와 척박한 땅에서 싹 을 틔워 가지들을 뻗고 자라는 우슬초는 바위틈과 돌밭에서 도 예쁜 꽃을 피우며 여러 포기가 한데 엉켜 무성한 떨기를 이루고 있어 아무리 핍박을 받아도 다시 일어나고, 한 곳에 서 상해를 입으면 흩어져서 번성하는 이스라엘 민족의 강인 함을 닮고 있다(3).

중앙아시아와 남유럽이 원산지인 히솝의 잎은 육류요리 와 생선요리의 향신료로 사용되며, 독특한 방향 성분은 주 류에 풍미를 더하고, 매운 맛을 내는 말빈 성분은 거담작용 을 하는 것으로 보고되고 있다(4). 히솝의 추출물에는 항바 
이러스작용이 있으며, 특히 구강 헤르페스를 일으키는 바 이러스에 효과적이다(5). 예전부터 히솝은 감기와 기관지 염에 효과가 있어 약초로 사용되었으며, 히솝차(茶)는 건위 작용, 초기 감기, 정신적 불안감, 가벼운 히스테리 등을 치료 하는 데에 도움이 된다(6,7). 히솝의 잎을 입욕제로 사용하 면 피부를 정화하고 냉증 개선에 효과가 있다고 보고되고 있다(8).

쌀의 종류 중 도정을 많이 한 백미는 당질이 $79.6 \%$ 나 되므로 각종 당화효소를 이용하여 당화시켜 우유나 베지밀 처럼 식사대용이나 음료용으로 개발할 수 있다(9). 쌀의 당화에는 보통 전분질의 액화를 목적으로 사용되는 $a$ -amylase와 액화된 당액을 포도당으로 분해하기 위해 사용 되는 효소로는 $\beta$-amylase와 glucoamylase가 있다. 그러나 상업적으로는 glucoamylase를 많이 사용한다. a-amylase는 amylose와 amylopectin의 a-1,4-glucan 결합을 내부에서 불 규칙하게 가수분해 시키는 효소이고, 액화형 효소라고도 한다. 그리고 glucoamylase는 a-1,4-glucan 결합을 절단하지 만, a-amylase와는 달리 전분의 비환원 말단으로부터 glucose를 한 개씩 차례로 절단한다. 따라서 glucose와 여러 가지 분자량의 dextrin으로 분해하는 효소이다(10).

따라서 본 연구에서는 우리의 주식인 쌀과 건강기능성을 가지고 있는 히솝을 이용하여 건강용 음료로 즐겨 마실 수 있는 히솝 쌀음료를 개발하고자 히솝 추출 및 쌀 당화 시 당도, 황색도 및 관능적 품질 특성의 변화를 모니터링한 후 추출 및 당화의 최적조건을 설정해 보았다.

\section{재료 및 방법}

\section{실험재료}

본 실험에 사용한 히솝(Hyssopus officinalis)은 대구약령 시 한약도매상에서 구입하여 마쇄기(SFM-353NK, SHINIL Co., Ltd., Seoul, Korea)로 조분쇄한 후 쌀음료 제조에 사용 하였다. 당화에 사용된 효소는 a-amylase(BAN 480L, Novozymes, Bagsvaerd, Denmark) $5 \mathrm{~mL}$ 와 glucoamylase (AMG 300L, Novozymes, Bagsvaerd, Denmark) $10 \mathrm{~mL}$ 를 $100 \mathrm{~mL}$ 메스플라스크에 넣은 후 증류수로 정용 희석하여 amylase 혼합액을 제조하여 사용하였다.

\section{쌀음료의 제조 실험계획}

쌀음료의 제조는 쌀 $500 \mathrm{~g}$ 에 물 $1.5 \mathrm{~L}$ 를 첨가하여 고두밥 을 제조한 후 여기에 증류수 $2 \mathrm{~L}$ 를 더 첨가한 다음 amylase 혼합액과 조분쇄된 구절초를 첨가하여 $55^{\circ} \mathrm{C}$ 에서 당화 시간 별로 당화시켰다. 당화가 끝난 용액은 착즙 후 Whatman No. 2 여과지로 여과하여 검사용 시료로 사용하였다. 히솝 첨가량 및 당화조건을 설정하기 위한 실험계획은 중심합성 실험계획법(11)에 따라 amylase 혼합액 첨가량 $(1,2,3,4$,
$5 \mathrm{~mL})$, 당화시간 $(10,12,14,16,18 \mathrm{hr})$ 및 히솝 첨가량 $(1.0$, $1.5,2.0,2.5,3.0 \mathrm{~g})$ 을 -2. $-1,0,1,2$ 로 다섯 단계로 부호화하 여 중심합성실험계획을 수립하였다. 또한 이들 요인변수에 의해 영향을 받는 종속변수 $\left(\mathrm{Y}_{\mathrm{n}}\right)$, 즉 당도 $\left(\mathrm{Y}_{1}\right)$, 황색도 (Hunter's color b) $\left(\mathrm{Y}_{2}\right)$ 및 관능적 특성으로 색상 $\left(\mathrm{Y}_{3}\right)$, 향 $\left(\mathrm{Y}_{4}\right)$, 맛 $\left(\mathrm{Y}_{5}\right)$, 전반적인 기호도 $\left(\mathrm{Y}_{6}\right)$ 로 하였으며, 이들은 3 회 반복 측정하여 그 평균값을 회귀분석에 사용하였다. 반응표면 회귀분석을 위해서는 statistical analysis system(SAS) program 을 사용하였으며(12), 독립변수의 변화에 따른 종속변수들 의 특성을 모니터링 하고자 Mathematica program을 이용하 여 4차원 반응표면으로 나타내었다(13).

\section{당도 측정}

발효액의 당함량은 hand refractometer(507-1, Nippon Optical Works Co., Tokyo, Japan)를 사용하여 3회 반복하여 측정하였다.

\section{색도 측정}

색도는 색차계(CT-310, Minolta Co., Osaka, Japan)를 사 용하여 3회 반복 측정하여 Hunter 방식인 b 값을 평균값으 로 나타내었으며, 이 때 사용된 표준 백반의 $\mathrm{b}$ 값은 2.18 이었 다.

\section{관능검사}

관능적 품질평가는 대학생들을 대상으로 시료에 대한 충분한 지식과 용어, 평가기준 등을 숙지시킨 후 동일한 쌀음료를 5 회 반복하여 관능검사를 행한 후 F-검정으로 차이식별 능력이 있는 16 명을 선발하여 관능검사를 실시하 였다. 관능평가는 히솝쌀음료 $100 \mathrm{~mL}$ 를 보고 마시면서 5점 채점법(14)으로 검사하였으며, 5점 '매우 좋다', 1점 매우 '나쁘다'로 나타내었다. 관능검사는 한 번에 3종류의 시료 를 제시하여 검사하는 균형 불완전블럭계획법(15)으로 색 상, 향, 맛 및 전반적인 기호도에 대하여 실시하였다.

\section{결과 및 고찰}

\section{당도 변화}

대부분의 음료는 당함량이 높고 고유의 향미를 가지고 있어 관능적으로 선호되고 있다. 히솝 쌀음료 또한 쌀음료 고유의 단맛에 히솝의 향미를 가미한 히솝쌀음료 특유의 맛을 형성할 필요가 있다. 히솝쌀음료에 당함량을 높이고 자 쌀을 당화시켜 본 결과, 당도의 범위가 $8.2^{\circ} 9.8^{\circ} \mathrm{Brix}$ 로 큰 차이가 없었다(Table 1). 이를 회귀 분석한 결과 당도의 $\mathrm{R}^{2}$ 는 0.8925 로 $5 \%$ 이내 유의수준에서 유의성이 인정되었 다(Table 2). 당화 중 당도의 변화는 히솝 함량에 따른 변화 는 거의 없고 amylase 함량이 증가할수록 증가하고 당화시 
Table 1. Experimental data on sugar concentration, Hunter's color b value and organoleptic properties of the hyssop (Hyssopus officinalis) granule under different conditions based on the central composite design for response surface analysis

\begin{tabular}{|c|c|c|c|c|c|c|c|c|c|}
\hline \multirow{2}{*}{$\begin{array}{l}\operatorname{Exp}_{1} \\
\text { No. }\end{array}$} & \multirow{2}{*}{$\begin{array}{l}\text { Content of } \\
\text { amylase (mL) }\end{array}$} & \multirow{2}{*}{$\begin{array}{l}\text { Amylase } \\
\text { treatment time } \\
(\mathrm{hr})\end{array}$} & \multirow{2}{*}{$\begin{array}{l}\text { Content of hyssop } \\
\text { (g) }\end{array}$} & \multirow{2}{*}{$\begin{array}{l}\text { Sugar conc. } \\
\left({ }^{\circ} \text { Brix }\right)\end{array}$} & \multirow{2}{*}{$\begin{array}{l}\text { Hunter's color } \\
\text { b value }\end{array}$} & \multicolumn{4}{|c|}{ Organoleptic properties } \\
\hline & & & & & & Color & Aroma & Taste & Overall palatability \\
\hline 1 & $2(-1)$ & $12(-1)$ & $1.5(-1)$ & 8.6 & 12.94 & $3.3^{2)}$ & 3.3 & 2.0 & 2.3 \\
\hline 2 & $2(-1)$ & $12(-1)$ & $2.5(1)$ & 8.6 & 13.43 & 3.3 & 3.0 & 2.3 & 2.7 \\
\hline 3 & $2(-1)$ & $16(1)$ & $1.5(-1)$ & 8.9 & 13.50 & 3.7 & 3.0 & 2.3 & 2.6 \\
\hline 4 & $2(-1)$ & $16(1)$ & $2.5(1)$ & 8.9 & 14.40 & 3.0 & 2.7 & 2.7 & 2.7 \\
\hline 5 & $4(1)$ & $12(-1)$ & $1.5(-1)$ & 9.0 & 11.88 & 3.3 & 3.7 & 3.0 & 3.7 \\
\hline 6 & $4(1)$ & $12(-1)$ & $2.5(1)$ & 9.0 & 12.09 & 3.0 & 2.7 & 3.3 & 3.5 \\
\hline 7 & $4(1)$ & $16(1)$ & $1.5(-1)$ & 9.2 & 11.89 & 4.0 & 2.7 & 3.3 & 3.3 \\
\hline 8 & $4(1)$ & $16(1)$ & $2.5(1)$ & 9.2 & 12.50 & 3.3 & 2.5 & 3.0 & 3.0 \\
\hline 9 & $3(0)$ & $14(0)$ & $2.0(0)$ & 8.7 & 12.86 & 3.3 & 2.7 & 2.3 & 3.3 \\
\hline 10 & $3(0)$ & $14(0)$ & $2.0(0)$ & 8.7 & 12.90 & 3.7 & 2.7 & 2.3 & 3.3 \\
\hline 11 & $1(-2)$ & $14(0)$ & $2.0(0)$ & 8.2 & 13.54 & 3.3 & 2.7 & 1.7 & 1.7 \\
\hline 12 & $5(2)$ & $14(0)$ & $2.0(0)$ & 9.8 & 12.32 & 3.7 & 3.0 & 2.7 & 2.7 \\
\hline 13 & $3(0)$ & $10(-2)$ & $2.0(0)$ & 8.5 & 12.81 & 2.3 & 3.7 & 2.5 & 2.0 \\
\hline 14 & $3(0)$ & $18(2)$ & $2.0(0)$ & 9.2 & 14.21 & 3.0 & 3.0 & 3.0 & 2.3 \\
\hline 15 & $3(0)$ & $14(0)$ & $1.0(-2)$ & 9.0 & 12.31 & 3.3 & 3.3 & 2.3 & 2.7 \\
\hline 16 & $3(0)$ & $14(0)$ & $3.0(2)$ & 9.0 & 14.13 & 2.3 & 3.0 & 2.7 & 2.7 \\
\hline
\end{tabular}

${ }^{11}$ The number of experimental conditions by central composite design.

${ }^{2)}$ Data were expressed as mean of triplicate determinations.

Table 2. Polynomial equations calculated by the RSM program for hyssop-rice drink

\begin{tabular}{|c|c|c|c|c|}
\hline \multicolumn{2}{|c|}{ Responses } & Polynomial equations ${ }^{1)}$ & $\mathrm{R}^{2}$ & Significance \\
\hline \multicolumn{2}{|c|}{ Sugar concentration } & $\begin{array}{c}\mathrm{Y}_{1}=9.99375+0.0125 \mathrm{X} 1-0.15 \mathrm{X} 2-1.2 \mathrm{X} 3+0.075 \times 12-0.0125 \mathrm{X} 1 \mathrm{X} 2 \\
+0.009375 \times 22+0.3 \times 32\end{array}$ & 0.8925 & 0.0249 \\
\hline \multicolumn{2}{|c|}{ Hunter's color $b$ value } & $\begin{array}{c}\mathrm{Y}_{2}=19.008125+0.659375 \times 1-0.948438 \times 2-1.61875 \times 3+0.0125 \times 12-0.069375 \times 1 X 2 \\
+0.039375 \times 22-0.1425 \times 1 \times 3+0.10125 \times 2 \times 3+0.340 \times 32\end{array}$ & 0.8698 & 0.0415 \\
\hline \multirow{3}{*}{ Organoleptic properties } & Color & $\begin{aligned} Y_{3}= & =11.9-0.56875 \times 1+1.671875 \times 2+4.4875 \times 3+0.05625 \times 1 X 2 \\
& -0.053125 \times 22-0.075 \times 1 \times 3-0.1375 \times 2 \times 3-0.7 \times 32\end{aligned}$ & 0.8841 & 0.0304 \\
\hline & Aroma & $\begin{array}{l}Y_{4}=15.05625+0.6125 \times 1-1.325 \times 2-3.05 \times 3+0.0375 \times 12 \\
-0.0375 \times 1 \times 2+0.040625 \times 22-0.15 \times 1 \times 3+0.1 \times 2 \times 3+0.45 \times 32\end{array}$ & 0.8672 & 0.0436 \\
\hline & Taste & $\begin{aligned} Y_{5}=1.7875 & +1.44375 \times 1-0.478125 \times 2+0.7875 \times 3-0.025 \times 12-0.04375 \times 1 X 2 \\
& +0.028125 \times 22-0.175 \times 1 \times 3-0.0625 \times 2 \times 3+0.2 \times 32\end{aligned}$ & 0.8290 & 0.0835 \\
\hline \multicolumn{2}{|c|}{ Overall palatability } & $\begin{array}{l}Y_{6}=-22.49375+3.525 \times 1+2.3375 \times 2+3.85 \times 3-0.275 \times 12 \\
-0.075 \times 1 \times 2-0.071875 \times 22-0.25 \times 1 \times 3-0.05 \times 2 \times 3-0.6 \times 32\end{array}$ & 0.8264 & 0.0867 \\
\hline
\end{tabular}

${ }^{1)} \mathrm{X} 1$, content of amylase (mL); X2, amylase treatment time (hr); X3, content of hyssop (g).

간이 길어질수록 증가하는 경향을 타나내었다(Fig. 1). 히솝 은 amylase의 당화에는 거의 영향을 미치지 않았는데, Table 4 에서 보는 바와 같이 히솝의 영향은 거의 없고 amylase 함량의 영향이 가장 높게 나타났다. 그 다음 순으로 당화시 간으로 나타났다. 당화 중 당함량이 가장 많이 생성되는 조건은 amylase 함량 $4.96 \mathrm{~mL}$, 당화시간 $14.93 \mathrm{hr}$ 및 히솝 함량 $2 \mathrm{~g}$ 에서 $9.62^{\circ} \mathrm{Brix}$ 로 나타났다. 당 함량이 가장 적게 생성되는 조건은 amylase 함량 $1.51 \mathrm{~mL}$, 당화시간 11.33 $\mathrm{hr}$ 및 히솝 함량 $2 \mathrm{~g}$ 에서 $8.27^{\circ} \mathrm{Brix}$ 로 나타났다(Table 3).

\section{색도 변화}

쌀만을 당화시켰을 때는 맑은 색이 나타나나 히솝을 넣 어 당화시켰을 때는 히솝 고유의 색소가 추출되어 히솝쌀음 료 특유의 색상을 띄게 된다. 당화과정 중 황색도의 변화를 관찰해 본 결과, 당화조건의 변화에 따른 Hunter's color $\mathrm{b}$ 값인 황색도가 11.88 14.21의 범위를 나타내었다(Table 

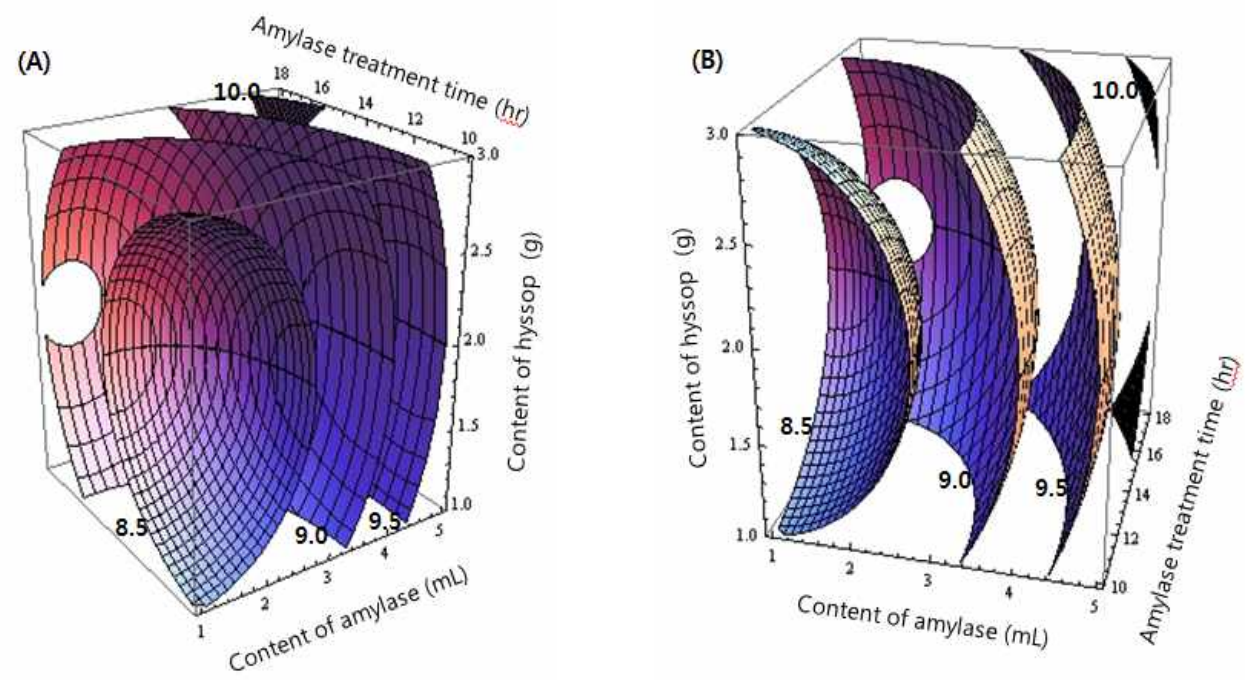

Fig. 1. Response surfaces for sugar concentration of the hyssop-rice drink at constant values $\left({ }^{\circ}\right.$ Brix : 8.5-9.0-9.5-10.0, (A)=(B)) based amylase content, amylase treatment time and hyssop content.
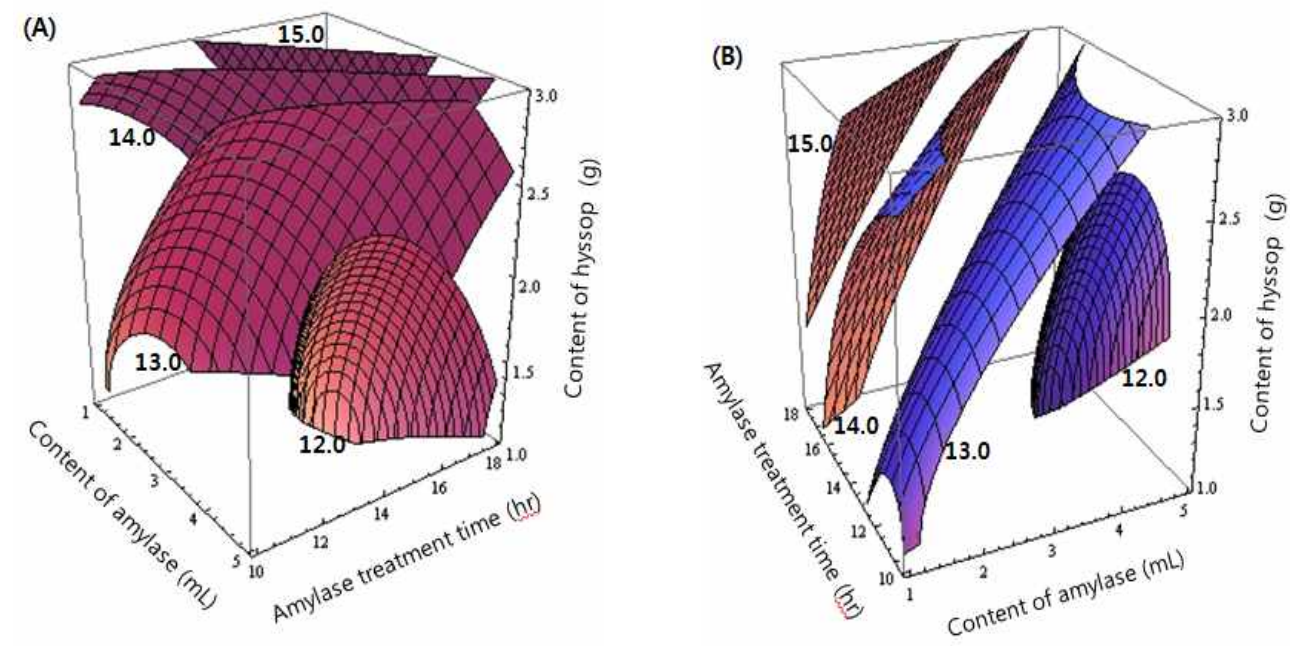

Fig. 2. Response surfaces for yellow color intensity of the hyssop-rice drink at constant values (Hunter's color b value : 12.0-13.0-14.0-15.0, $(A)=(B))$ based amylase content, amylase treatment time and hyssop content.

1). 이를 회귀 분석한 결과 Hunter's color $b$ 값의 $R^{2}$ 는 각각 0.8698 로 $5 \%$ 이내 유의수준에서 유의성이 인정되었다 (Table 2). Hunter's color b값은 amylase 함량이 감소하고 당화시간이 길어질수록 황색도가 증가하는 것으로 나타났 으며, 히솝 함량이 증가할수록 황색도가 증가하는 것으로 나타났다(Fig. 2). 당화조건이 Hunter's color b값에 미치는 영향은 amylase 함량이 높게 나타났으며, 다음으로 히솝 함량이 높게 나타났으나 당화시간과는 큰 차이를 보이지 않았다(Table 4). 황색도인 Hunter's color b가 가장 높게 나타나는 조건은 amylase 함량 $1.90 \mathrm{~mL}$, 당화시간 16.64 $\mathrm{hr}$ 및 히솝 함량 $2.51 \mathrm{~g}$ 에서 14.86 으로 나타났다. 이것은 당함량이 낮은 상태에서 긴 시간 당화시 히솝이 잘 추출되
어 나와서 당에 의한 갈변이 줄어들고 히솝 고유의 황색이 나타났기 때문으로 여겨진다. 한편, Hunter's color b값이 가장 적게 나타나는 조건은 amylase 함량 $4.91 \mathrm{~mL}$, 당화시 간 $14.10 \mathrm{hr}$ 및 히솝 함량 $1.71 \mathrm{~g}$ 에서 11.67 로 나타났다(Table 3). 이러한 현상은 amylase 함량이 높고 당화시간이 길어질 수록 가수분해 된 많은 당이 긴 시간이 경과하면서 갈변되 었기 때문으로 여겨진다.

\section{관능적 품질 특성}

히솝쌀음료의 관능적 색상에 대한 관능평점은 2.3 4.0의 범위를 나타내었으며(Table 1), 색상에 대한 4차원 반응표 면 회귀식의 $\mathrm{R}^{2}$ 는 0.8841 로서 $5 \%$ 의 유의수준에서 유의성 
Table 3. Estimated levels of optimum preparation conditions for the hyssop-rice drink

\begin{tabular}{|c|c|c|c|c|c|c|c|c|c|c|}
\hline \multirow{3}{*}{\multicolumn{2}{|c|}{ Responses }} & \multicolumn{6}{|c|}{ Preparation conditions } & \multirow{2}{*}{\multicolumn{2}{|c|}{ Estimated responses }} & \multirow{3}{*}{ Morphology } \\
\hline & & \multicolumn{2}{|c|}{ Content of amylase $(\mathrm{mL})$} & \multicolumn{2}{|c|}{$\begin{array}{l}\text { Amylase treatment time } \\
(\mathrm{hr})\end{array}$} & \multicolumn{2}{|c|}{ Content of hyssop (g) } & & & \\
\hline & & Max. & Min. & Max. & Min. & Max. & Min. & Max. & Min. & \\
\hline \multicolumn{2}{|c|}{ Sugar concentration } & 4.95 & 1.51 & 14.93 & 11.33 & 2.00 & 2.00 & 9.62 & 8.27 & Minimum \\
\hline \multicolumn{2}{|c|}{ Hunter's color b value } & 1.90 & 4.91 & 16.64 & 14.10 & 2.51 & 1.71 & 14.86 & 11.67 & Saddle point \\
\hline \multirow{3}{*}{$\begin{array}{l}\text { Organoleptic } \\
\text { properties }\end{array}$} & Color & 4.60 & 2.81 & 15.66 & 15.80 & 1.57 & 2.89 & 4.09 & 2.39 & Saddle point \\
\hline & Aroma & 3.46 & 4.23 & 10.79 & 15.31 & 1.45 & 2.39 & 3.99 & 2.55 & Minimum \\
\hline & Taste & 3.67 & 1.22 & 17.64 & 12.83 & 1.76 & 1.64 & 3.17 & 1.49 & Saddle point \\
\hline \multicolumn{2}{|c|}{ Overall palatability } & 3.73 & 1.31 & 13.66 & 12.07 & 1.85 & 1.77 & 3.61 & 1.50 & Maximum \\
\hline
\end{tabular}
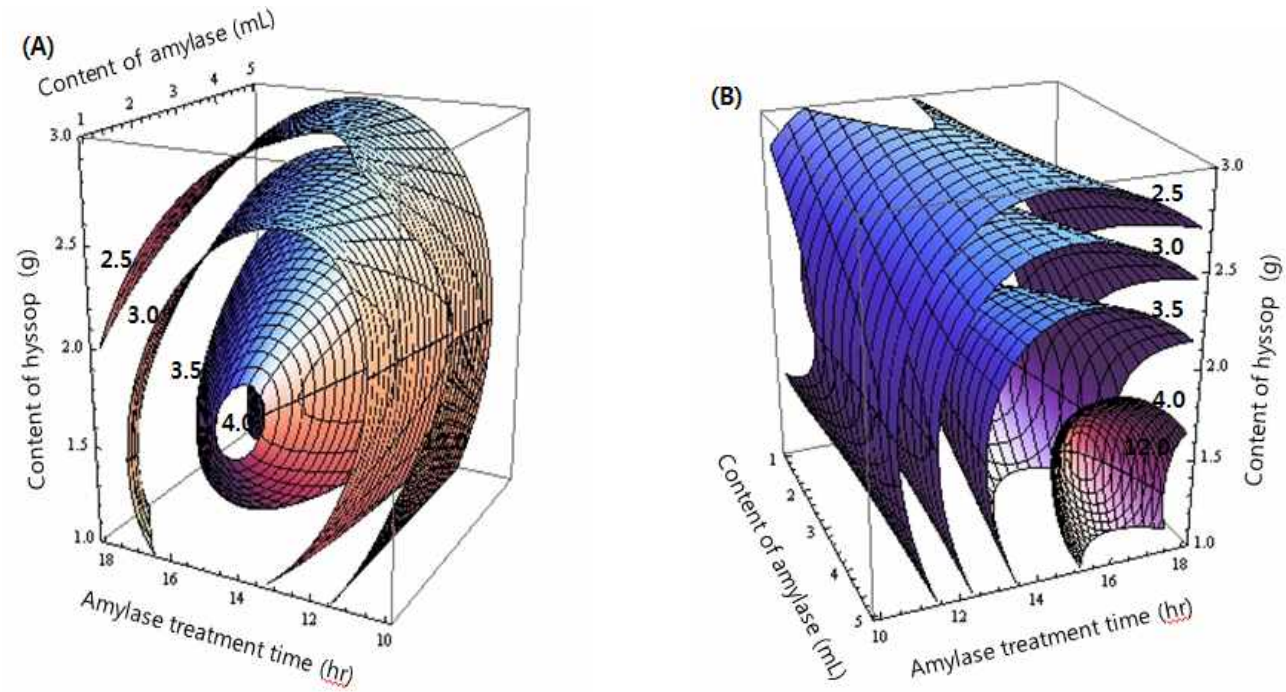

Fig. 3. Response surfaces for organoleptic color of the hyssop-rice drink at constant values (sensory score : 2.5-3.0-3.5-4.0, (A)=(B)) based amylase content, amylase treatment time and hyssop content.

이 인정되었다(Table 2). 히솝쌀음료의 색상은 amylase 함량 이 증가하고 당화시간이 길어질수록 증가하는 경향을 나타 내었으며, 히솝 함량은 $2 \mathrm{~g}$ 이하에서 높은 관능평점을 나타 내었다(Fig. 3). 이러한 경향은 황색도와는 반대의 경향으로 황색도가 낮은 조건에서 색상에 대한 선호도가 높은 것을 알 수 있었다. 히솝쌀음료 제조조건이 색상에 대해 미치는 영향은 히솝 함량이 가장 큰 영향을 미쳤으며, 다음으로 당화시간이 히솝 함량과 비슷한 영향을 미치는 것으로 나타 났다. 그러나 amylase 함량은 색상에 대한 관능점수에는 거의 영향을 미치지 않았다(Table 4). 색상에 대한 4차원 반응모형은 안장점의 형태를 나타내었으며, 최대의 관능평 점은 amylase 함량 $4.60 \mathrm{~mL}$, 당화시간 $15.66 \mathrm{hr}$ 및 히솝 함량 $1.57 \mathrm{~g}$ 에서 4.09 로 나타났다. 최소의 관능평점은 amylase 함량 $2.81 \mathrm{~mL}$, 당화시간 $15.80 \mathrm{hr}$ 및 히솝 함량 $2.89 \mathrm{~g}$ 에서 2.39로 나타났다(Table 3). 히솝 함량이 낮아서 연한 황색을 나타내는 조건에서 제조된 히솝쌀음료가 색상 에서는 더 선호되는 것으로 여겨진다.
향미에 대한 관능평정은 2.7 3.7의 범위를 나타내었으며 (Table 1), 반응표면분석에 따른 향미 또한 4차원 반응표면 회귀식의 $\mathrm{R}^{2}$ 가 0.8672 로서 $5 \%$ 의 유의수준에서 유의성이 인정되었다(Table 2). 히솝쌀음료의 향미는 당화시간이 짧 고 히솝 함량이 낮은 조건에서 높은 것으로 나타났으며, amylase 함량의 변화에 대한 향미의 변화는 미미하였다 (Fig. 3). 이러한 경향은 당화가 진행되면서 높아지는 발효 취와 히솝의 향미가 높은 것을 선호하지 않는 것으로 여겨 진다. 히솝쌀음료의 향미에 대한 영향은 당화시간이 가장 크게 영향을 미쳤으며, 다음으로 히솝 함량이 영향을 미쳤 으나, amylase 함량은 거의 영향을 미치지 않는 것으로 나타 났다(Table 4). 향미에 대한 4차원 반응모형은 최소점의 형 태를 나타내었으며, 능선분석을 해 본 결과, 향미에 대한 최대의 관능평점은 amylase 함량 $3.46 \mathrm{~mL}$, 당화시간 10.79 $\mathrm{hr}$ 및 히솝 함량 $1.45 \mathrm{~g}$ 에서 3.99 로 나타났다. 최소의 관능평 점은 amylase 함량 $4.23 \mathrm{~mL}$, 당화시간 $15.31 \mathrm{hr}$ 및 히솝 함량 $2.39 \mathrm{~g}$ 에서 2.55로 나타났다(Table 3). 
Table 4. Regression analysis for the regression model of sugar concentration, Hunter's color b value and organoleptic properties in the preparation of the hyssop-rice drink

\begin{tabular}{|c|c|c|c|}
\hline \multirow[b]{2}{*}{ Regression model } & \multicolumn{3}{|c|}{ F-value of preparation conditions } \\
\hline & $\begin{array}{l}\text { Content of } \\
\text { amylase (mL) }\end{array}$ & $\begin{array}{l}\text { Amylase treatment } \\
\text { time (hr) }\end{array}$ & $\begin{array}{l}\text { Content of } \\
\text { hyssop }(\mathrm{g})\end{array}$ \\
\hline $\mathrm{Y}_{\text {Sugar concentration }}$ & $9.75^{\star \star * *}$ & 2.66 & 0.62 \\
\hline$Y_{\text {Hunter's color } b \text { value }}$ & $5.25^{\star *}$ & 2.35 & 2.74 \\
\hline$Y_{\text {Oragnoleptic color }}$ & 0.77 & $5.56^{* *}$ & $6.15^{* *}$ \\
\hline$Y_{\text {Oragnolpic aroma }}$ & 0.67 & $6.91^{* *}$ & $4.00^{*}$ \\
\hline$Y_{\text {Oragnoleptic taste }}$ & $15.31^{* \star}$ & 1.34 & 0.77 \\
\hline$Y_{\text {Overall palatability }}$ & $6.12^{\star \star}$ & 2.91 & 0.96 \\
\hline
\end{tabular}

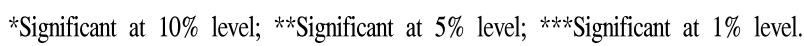

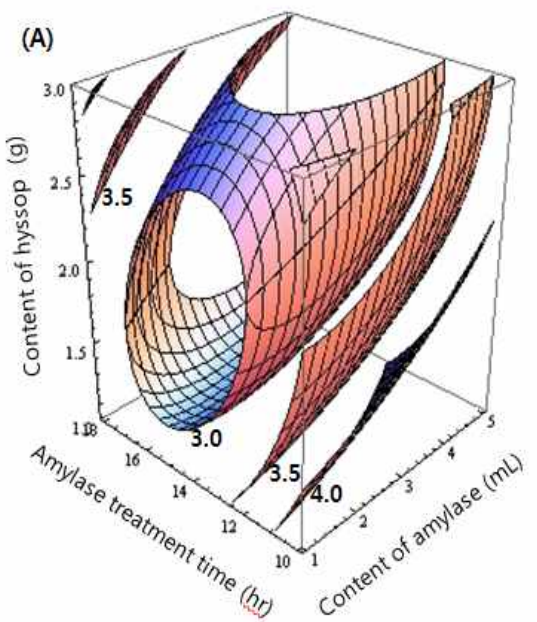

히솝쌀음료의 맛에 대한 관능평정은 1.7 3.3의 범위를 나타내어 전반적으로 낮게 나타났으며(Table 1), 반응표면 분석에 따른 향미 또한 4차원 반응표면 회귀식의 $\mathrm{R}^{2}$ 가 0.8290 로서 $10 \%$ 의 유의수준에서 유의성이 인정되었다 (Table 2). 히솝 음료의 맛은 amylase 함량이 높은 조건에서 당화가 충분히 진행된 음료가 더 선호되는 것으로 나타났으 며, 히솝 함량의 변화에는 거의 변화가 없었다(Fig. 3). 이러 한 경향은 당화가 진행되면서 단맛이 증가하여 풍부한 맛을 부가하였기 때문으로 여겨진다. 히솝쌀음료의 맛에 대한 영향은 amylase 함량이 가장 크게 영향을 미쳤으며, 상대적 으로 당화시간과 히솝 함량은 낮은 것으로 나타났다(Table 4). 이러한 경향은 색상의 변화와 유사였다. 맛에 대한 4차 원 반응모형은 안장점의 형태를 나타내었으며, 능선분석을

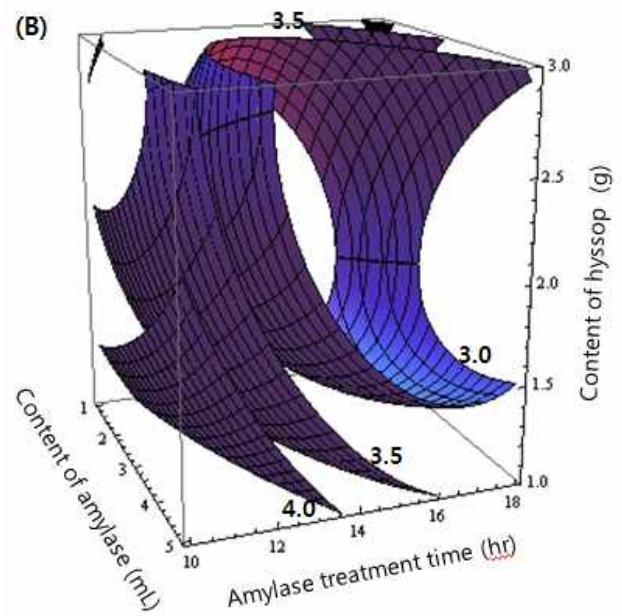

Fig. 4. Response surfaces for organoleptic aroma of the hyssop-rice drink at constant values (sensory score : $3.0-3.5-4.0$, (A)=(B)) based amylase content, amylase treatment time and hyssop content.
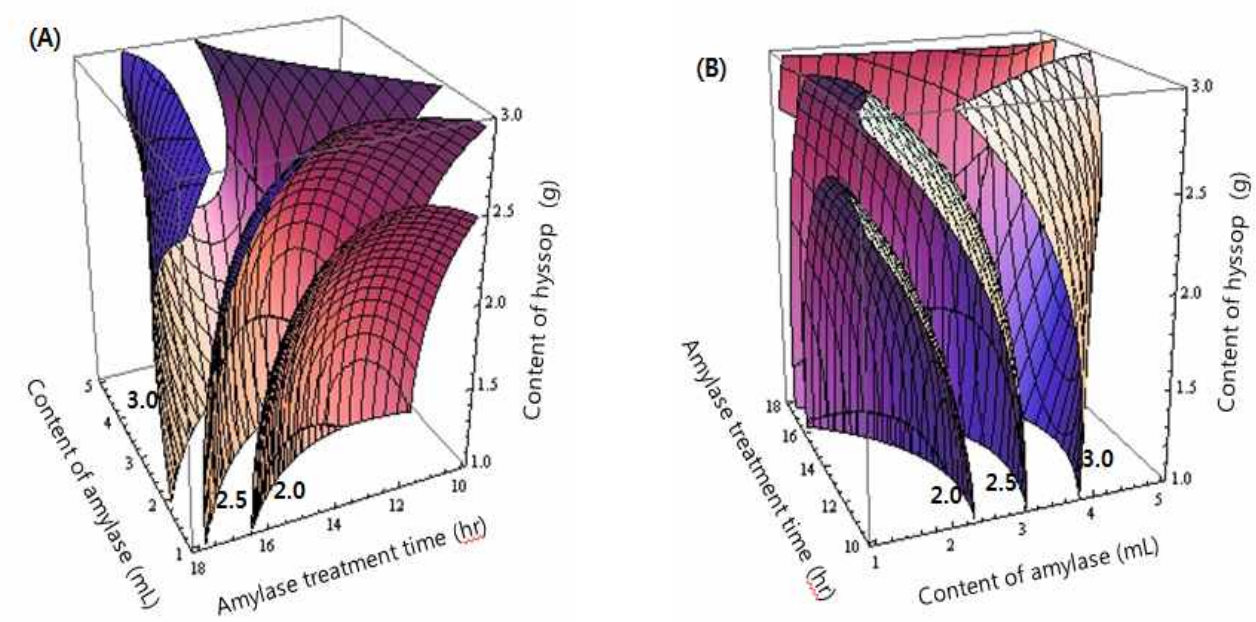

Fig. 5. Response surfaces for or ganoleptic taste of the hyssop-rice drink at constant values (sensory score : 2.0-2.5-3.0, (A)=(B)) based amylase content, amylase treatment time and hyssop content. 

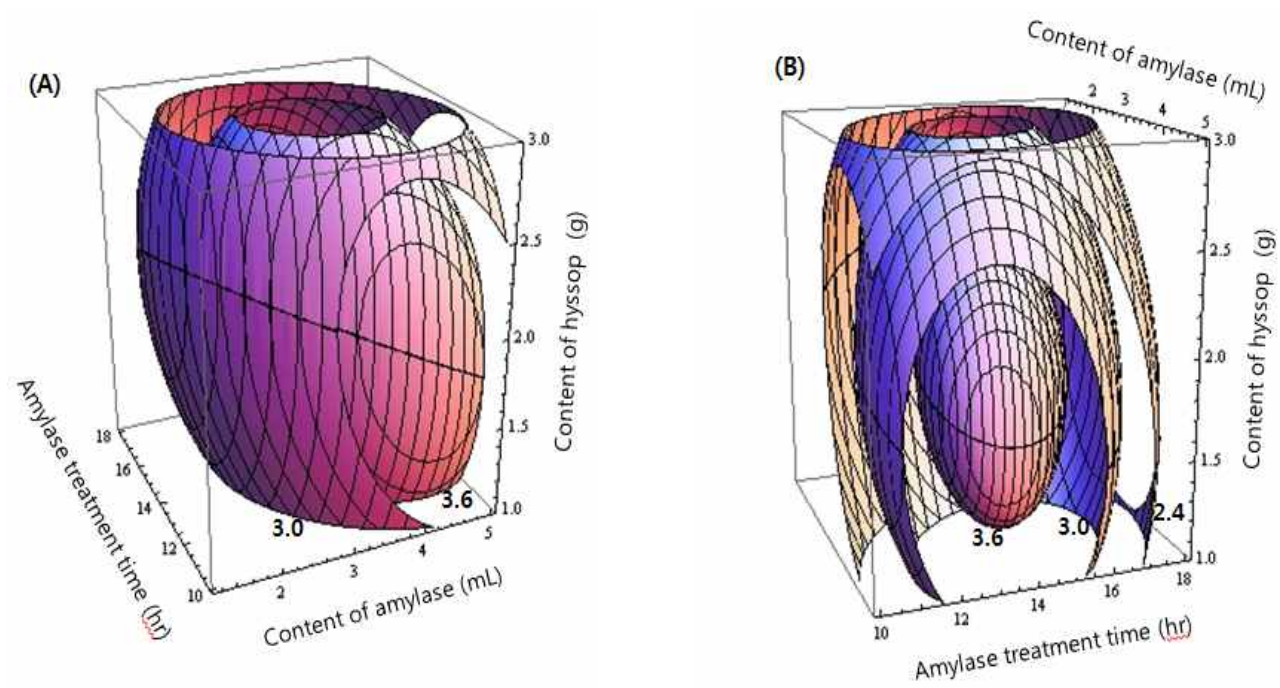

Fig. 6. Response surfaces for overall palatability of the hyssop-rice drink at constant values (sensory score : 2.4-3.0-3.6, (A)=(B)) based amylase content, amylase treatment time and hyssop content.

해 본 결과, 맛에 대한 최대의 관능평점은 amylase 함량 $3.67 \mathrm{~mL}$, 당화시간 $17.64 \mathrm{hr}$ 및 히솝 함량 $1.76 \mathrm{~g}$ 에서 3.17 로 나타났다. 최소의 관능평점은 amylase 함량 $1.22 \mathrm{~mL}$, 당화 시간 $12.83 \mathrm{hr}$ 및 히솝 함량 $1.64 \mathrm{~g}$ 에서 1.49 로 나타났다 (Table 3).

히솝쌀음료의 전반적인 기호도에 대한 관능평점은 1.7 3.7의 범위를 나타내어 넓은 범위를 나타내었으며 (Table 1), 반응표면분석에 따른 전반적인 기호도는 4차원 반응표면 회귀식의 $\mathrm{R}^{2}$ 가 0.8264 로서 $10 \%$ 의 유의수준에서 유의성이 인정되었다(Table 2). 히솝쌀음료의 전반적인 기 호도에 대한 4차원 반응모형은 최대점의 형태를 나타내었 으며, 능선분석을 해 본 결과, 전반적인 기호도에 대한 최대 의 관능평점은 amylase 함량 $3.73 \mathrm{~mL}$, 당화시간 $13.66 \mathrm{hr}$ 및 히솝 함량 $1.85 \mathrm{~g}$ 에서 3.61로 가장 높게 나타났다(Table 3). Fig. 6의 중심부에 있는 최대점으로부터 음료제조조건 이 벗어날수록 전반적인 기호도가 낮아지는 경향을 나타내 었으며(Fig. 3), 이러한 경향은 색상, 향미, 맛 등이 종합적으 로 융합되어 나타난 것으로 여겨진다. 히솝쌀음료의 전반 적인 기호도에 대한 영향은 amylase 함량이 가장 크게 영향 을 미쳤으며, 다음으로 당화시간이 높게 나타났으며, 히솝 함량은 거의 영향을 미치지 않는 것으로 나타났다(Table 4). 이러한 경향은 맛의 변화와 유사한 경향이었으나 색상 및 향미의 경향과는 반대로 나타났다.

따라서 관능적 선호도는 특정 중심점(amylase 함량 3.73 $\mathrm{mL}$, 당화시간 $13.66 \mathrm{hr}$ 및 히솝 함량 $1.85 \mathrm{~g}$ )에서 만들어진 히솝쌀음료가 가장 높은 것으로 나타나 히솝쌀음료의 최적 제조조건으로 설정할 수 있었다.

\section{요 약}

쌀과 히솝을 이용하여 히솝쌀음료를 가공하고자 제조특 성을 조사하였다. 히솝쌀음료의 제조조건은 amylase 함량 $\left(\mathrm{X}_{1}, 1 \sim 5 \mathrm{~mL}\right)$, 당화시간 $\left(\mathrm{X}_{2}, 10 \sim 18 \mathrm{hr}\right)$ 및 히솝 함량 $\left(\mathrm{X}_{3}\right.$, $1.0 \sim 3.0 \mathrm{~g}$ )으로 당화 후 당도, 황색도, 관능적 특성을 반응표 면분석을 통하여 모니터링 하였다. 당화 중 당 함량이 가장 많이 생성되는 조건은 amylase 함량 $4.96 \mathrm{~mL}$, 당화시간 $14.93 \mathrm{hr}$ 및 히솝 함량 $2 \mathrm{~g}$ 에서 $9.62^{\circ} \mathrm{Brix}$ 로 나타났다. 황색도 인 Hunter's color b가 가장 높게 나타나는 조건은 amylase 함량 $1.90 \mathrm{~mL}$, 당화시간 $16.64 \mathrm{hr}$ 및 히솝 함량 $2.51 \mathrm{~g}$ 에서 $14.86^{\circ} \mathrm{Brix}$ 로 나타났다. 색상에 대한 최대의 관능평점은 amylase 함량 $4.60 \mathrm{~mL}$, 당화시간 $15.66 \mathrm{hr}$ 및 히솝 함량 $1.57 \mathrm{~g}$ 에서 4.09로 나타났다. 향미에 대한 최대의 관능평점 은 amylase 함량 $3.46 \mathrm{~mL}$, 당화시간 $10.79 \mathrm{hr}$ 및 히솝 함량 $1.45 \mathrm{~g}$ 에서 3.99 로 나타났다. 맛에 대한 최대의 관능평점은 amylase 함량 $3.67 \mathrm{~mL}$, 당화시간 $17.64 \mathrm{hr}$ 및 히솝 함량 $1.76 \mathrm{~g}$ 에서 3.17 로 나타났다. 소비자의 종합적인 선호도를 나타내는 전반적인 기호도는 amylase 함량 $3.73 \mathrm{~mL}$, 당화시 간 $13.66 \mathrm{hr}$ 및 히솝 함량 $1.85 \mathrm{~g}$ 에서 3.61 로 가장 높게 나타 나 최적조건을 설정할 수 있었다.

\section{References}

1. Kum JS (2008) Blooming of rice processing industry. Food Indu Nutr, 13, 9-14

2. Won YJ, Oh SK (2014) Development of process using technology and rice varieties for aseptic-packaged cooked rice. Food Sci Indu, 47, 71-79 
3. Nam DG (2004) Hyssopus officinalis. Forest Cultu, 13, 32-39

4. Hossein K, Karamatollah R, Seyyed JG, Zahra ED, Yadollah Y (2007) Supercritical fluid extraction of flavors and fragrances from Hyssopus officinalis L. cultivated in Iran. Food Chem, 105, $805-811$

5. Letessier MP, Svoboda KP, Walters DR (2001) Antifungal activity of the essential oil of hyssop (Hyssopus officinalis). J Phytopathol, 149, 673-678

6. Lu M, Battinelli L, Daniele C, Melchioni C, Salvatore G, Mazzanti G (2002) Muscle relaxing activity of Hyssopus officinalis essential oil on isolated intestinal preparations. Planta Medi, 68, 213-216

7. Mazzanti1 G, Lu M, Salvatore G (1998) Spasmolytic action of the essential oil from Hyssopus officinalis L. var. decumbens and its major components. Phytotherapy Res, 12, $92-94$

8. Gorunovica MS, Bogavaca PM, Chalchatb JC, Chabard JL (1995) Essential oil of Hyssopus officinalis L., Lamiaceae of montenegro origin. J Essen Oil Res, 7,
$39-43$

9. Ju HG, Cho HG, Park CG, Cho GS, Chae SG, Ma SJ (1991) Methods of Food Analysis. Songlimmunhwasa, Yeosu, Korea, p 488-489

10. Lee GH (1997) Food Chemistry. Huyngseolchulpansa, Seoul, Korea, p 401-405

11. Myers RH (1971) Response Surface Methodology. Allyn and Bacon Inc., Boston, USA, p 132-133

12. SAS (1988) SAS/STAT : User's Guide Version 6, 4th ed, Statistical Analysis System Institute, Cary, NC, USA, p 1457-1478

13. Martha LA, James PB (1992) The Mathematica Handbook, Compatible with Mathematica Version 2.0. An Inprint of a Division of Academic Press, Inc., Harcourt Brace \& Co., Massachusetts, USA. p 15-511

14. Kim KO, Lee YC (1989) Sensory Test of Food. Hagyesa, Seoul, Korea, p 241-243

15. Park SH (1991) Modern Experimental Design. Minyoungsa, Seoul, Korea, p 547-557 